\title{
Embarrassment as a Key Emotion in Young People Talking About Sexual Health
}

\author{
by Edwin van Teijlingen, Jennifer Reid, Janet Shucksmith, Fiona Harris, Kate Philip, Mari \\ Imamura, Janet Tucker and Gillian Penney \\ University of Aberdeen; University of Aberdeen; University of Teesside; University of Edinburgh; \\ University of Aberdeen; University of Teesside: University of Aberdeen; University of Edinburgh
}

Sociological Research Online, Volume 12, Issue 2,

$<$ http://umw.socresonline.org.uk/12/2/van_teijlingen.html>

doi:10.5153/sro. 1535

Received: 18 May 2006 Accepted: 20 Mar 2007 Published: 30 Mar 2007

\begin{abstract}
This paper highlights embarrassment as one of the often-ignored emotions of young people when it comes to discussing issues around sexual health. There have been many sexual health studies on knowledge, attitudes and behaviour of young people over the past two decades, but emotional aspects have been largely ignored, despite a growing literature in the sociology of emotion.
\end{abstract}

A qualitative approach was adopted in the form of focus group discussions, which included questions on sex education, sexual health campaigns and formal and informal sources of sexual health information and advice. Focus groups were conducted in secondary schools in and around Edinburgh and Aberdeen as part of a four-year evaluation study of a Scottish Demonstration Project on young people's sexual health: 'Healthy Respect'.

We conclude that is it important for policy makers and sexual health promoters to understand young people's notions of embarrassment. Not only are there elements of sex education that (some) young people perceive as embarrassing, they also sense embarrassment in those people providing them with sex education. Young people reported that both professionals (e.g. teachers and doctors) and their parents could be embarrassed about raising the topic of sexual health. Moreover, as one of the goals of sex education is to ensure an open and non-embarrassing attitude towards sex and sexuality, there is still a major gap between the aspirations of health educators and policy makers and the ways that young people experience such education.

\section{Keywords: Sexual Health Services, Adolescence, School, Scotland, Emotion, Qualitative Research, Sex Education, Parents, Focus Groups, Relationships}

\section{Introduction}

1.1 Over the past two decades, since the start of the HIVIAIDS pandemic, a large number of sexual health studies have been conducted with young people. Many studies have highlighted important issues around knowledge (e.g. about the different ways sexually transmitted infections [STls] can spread), attitudes (e.g. towards contraceptive use) and behaviour (e.g. being able to talk to a sexual partner, or knowing how to use a condom properly). Studies on self-reported sexual behaviour have indicated that young people in the late twentieth century are becoming sexually active at an earlier age than before (Parratt \& Hay 2003; Wight et al. 2000).

1.2 Young people's emotions, however, have largely been ignored in the kind of prevalence or 'lifestyle' studies mentioned above. For example, in an interview-based study with 62 pregnant teenagers, notions of romantic love were "notable by their absence from respondents' explanations of how they came to be pregnant" (Finlay 1996: 80). Occasionally lifestyle studies have addressed aspects of emotions under other categories (Hochschild 1983: 201), for example under the banner of 'attitudes'.

\section{Emotions/embarrassment}

2.1 Emotions are typically complex, and mixed. Sociologists have argued that emotion is experienced in one's body as a subjective feeling, which is part of the transaction between oneself and another (Barbalet 2002: 4). As Williams (1998: 761) reminded us: "without emotions, social life, including our decision- 
making capacities and our ability to make informed choices among a plurality of options would be impossible." Hochschild (1983) in her seminal work The Managed Heart places emotions in the centre of the study of organisational and societal norms and values. She highlighted that emotions are not straightforward, involuntary physiological reactions expressed by the human body, but that they are socially constructed, or at least, influenced or shaped by social and cultural factors (Hochschild 1983; Finlay 1996). Emotions are guided by so-called 'emotions rules', which establish "the sense of entitlement or obligation that governs emotional exchanges" (Hochschild 1983: 56).

2.2 The term emotion covers for example: 'fear'; 'shame'; 'guilt'; 'depression'; 'anger'; 'surprise'; 'acceptance' or 'joy'. However, such emotions are not just individual reactions, but they are also shared in and shaped by groups, as our response to social norms, including providing the basis for social reciprocity and exchange (Wentworth \& Yardley 1994). Whilst some emotions develop more slowly than others, e.g. 'guilt' develops more slowly than 'shame', and hence the former is often regarded as an adult emotion (TenHouten 2007: $51)$.

2.3 Our paper focuses on 'embarrassment' as a key emotion in young people when discussing sex, sexual health and/or sex education. Embarrassment can be studied along the lines of the two traditions in the sociology of emotions recognised by Shilling (2002). One tradition focuses on the social order, and highlights issues such as, for example, control, social institutions such as the family, religion or education. In fact embarrassment has been referred to as the 'emotion of social control' (Parrott \& Harré 1996). The other sociological tradition focuses on (inter)action, where symbolic interactionists might see embarrassment as the emotion occurring when a person is unable to play any acceptable role given the dominant consensus (TenHouten 2007: 59). Symbolic interactionists would argue that emotions (help) shape the flow of interactions (Hochschild 1979). Hochschild (1983) made the distinction between surface and deep acting when we manage our emotions, in what she called, 'emotion work'. Surface acting is where one pretends to be or 'acts' as character $X$, whilst deep acting refers to one 'becoming' that particular character, through manipulating our emotions to produce 'authentic' responses.

2.4 In relation to young people, the negotiation of sexual encounters has been examined by Holland et al (1990). They argued that embarrassment over using condoms for example, needs to be set within the context of gendered power relationships between potentially unequal partners, rather than viewed as a simple practical matter. They demonstrate how, 'Young men may well be just as embarrassed in sexual encounters as young women, especially when they are inexperienced, but the meanings carried by condoms allow them to hide embarrassment by recourse to a public discourse which legitimates the rejection of condoms' (Holland et al., 1990:22)

2.5 Other emotions, particularly shame and humour, have been associated with embarrassment. Humour, perhaps in the form of joking about the topic that causes the embarrassment, can help relieve tension (e.g. Goffman 1967; Hay 2000), or hide the embarrassment (Chapple and Ziebland 2004). Perhaps the main link between humour and embarrassment is not so much that humour is denying "the same reality as embarrassment, but in helping to create the social reality of embarrassment (Billig 2001: 23)." In other words, humour helps to perpetuate, rather than dispel, the embarrassment as part of a wider social control.

\section{Growing up}

3.1 Young people go through a transition period from the relatively carefree years of childhood to achieving responsible adulthood (Schaie and Willis 1991: 37). However, unlike Schaie and Willis we would suggest that this is too simplistic as childhood per se is not necessarily 'carefree'. Nevertheless, the early teenage years represent a period of gradual transformation from concrete, short-term, self-focused abilities to more advanced abstract, future-oriented, decision-making abilities and the subordination of self-interest to relationship concerns (Kegan 1996). TenHouten (2007: 51) reminded us that "Just as the mastery of language gradually expands, so also does our repertoire of emotions. This process continues into adolescence and adulthood and is in fact a lifelong process." Although as Holdsworth and Morgan (2005: 88) suggested the "start and end points of youth transformations are not necessarily clearly demarcated states."

3.2 Generally this transformation period involves a wide-range of behavioural changes that come with 'growing up', such as (1) experimentation with drugs (including tobacco, marijuana, ecstasy, coffee and alcohol) or relationships (from kissing a first boy or girl friend to experiencing sexual intercourse); and (2) gaining responsibilities for one's own destiny at school and work (e.g.Rosenthal and Smith 1997). The existence of a range of youth transitions is now well recognised (Jones and Wallace, 1992; Coles, 1995; Bullock and Room 2006: 128), but sexuality and sexual matters in adolescence also raise emotional ambiguities and uncertainties both for young people and for adults that are less well recognised. In addition there are the underlying dynamics of power and control in social relationships (Shoveller and Johnson, 2006: 48), for example young people might not be, or might not perceive themselves to be, in relationships 
where negotiating safer sex is impossible. For example, Holland et al. (1992) highlighted that young women face major problems in negotiating safer sex due to their subordinate role in the sexual relationship, whilst Finlay (1996: 86) noted that "fear for one's reputation was the pre-eminent reason" for the reluctance of pregnant teenagers to carry condoms.

\section{School-based sex education}

4.1 One response to the HIVIAIDS pandemic has been the development of sexual health education, especially school-based sex and relationship education. For example, in the UK the 1993 Education Act legislated for the first time that sex education must be taught in all UK secondary schools (the equivalent of United States high schools). However, the government school inspection body, the Office for Standards in Education for England (2002: 5), commented that not all (over nine out of ten schools in their survey) had sex and relationship education policies, and that the quality of these policies was good in only three fifths of secondary schools. Several evaluations of sex education interventions that were mostly school-based have recently been published (e.g.Wight et al. 2002; Rolston et al. 2005). Sex education programmes are often implicitly or explicitly concerned with the improvement of communication between young people and teachers and young people and their parents or guardians and placing sexual intercourse and sex education with the wider perspective of young people's relationships.

4.2 The most recent large-scale sexual health promotion intervention in Scotland is Healthy Respect (McVea et al. 2001). The authors acted as the external independent evaluators of this government-funded intervention, which is outlined in the following paragraphs (Tucker et al. 2006).

\section{The evaluation of Healthy Respect}

5.1 Healthy Respect was established as a national health demonstration programme to improve the sexual health of young people in Scotland, including reducing teenage conceptions and STls by promoting a more informed and responsible approach to sexual matters (Scottish Office Department of Health 1999; McVea et al. 2001). The first phase of this demonstration project (2001-2004) was a partnership initiative bringing together health services, health promotion, education and voluntary sector agencies' projects and services under the brand of Healthy Respect in Lothian, the region in which Edinburgh is situated (Tucker et al. 2005). Our independent research team evaluated Healthy Respect from three perspectives: process of implementation; comparative regional mapping of service development and inter-agency partnership working; and comparative impact using quasi-experimental design and adjusted, population-based behavioural and sexual health outcomes (Tucker et al. 2006).

5.2 Our evaluation was to assess Healthy Respect's success against the intervention's own objectives and goals. Like Healthy Respect, we did not set out to explore young people's emotions, but as we incorporated a qualitative element into our research young people were given an opportunity to raise a range of issues important to them. During the analysis one of the key themes that appeared from the data was 'embarrassment'.

5.3 Our paper, therefore, explores the extent to which young people in secondary schools view sexual health, and sex and relationship education as embarrassing. It also explores notions of embarrassment associated in young people's accounts of agencies providing sexual health services and sex education.

\section{Methods}

6.1 We conducted 32 focus groups in secondary schools in Aberdeen and in Lothian region in the period 2002-2004. Focus groups are widely used in market research, media studies and health promotion research (Bowling 2002: 394). They have also been used with young people in similar sexual health studies in the UK (Wight 1994; Hyde et al. 2005) and beyond (Roberts et al. 2005; DiCenso et al. 2001). The interaction between focus group members allows for an element of deliberation. This interaction also enables group members to ask each other questions and to re-evaluate or reconsider their own understandings of their specific experiences (Gibbs 1997). One focus group participant discussing one particular aspect of the topic under debate can trigger off ideas (i.e. prompting) in other group members, who, like the facilitator, might not have thought about it (van Teijlingen and Pitchforth 2006). Thus group discussions "may uncover motivations that would not emerge in individual interviews. Moreover, group discussion may be better able to reveal intensity of feelings, thus comparisons among different positions" (Corbetta 2003: 276). Furthermore, some suggest that focus groups promote self-disclosure through mutual support (Kitzinger 1995; Kreuger and Casey 2000). As Macnaghten and Myers (2004: 65) suggested "focus groups work best for topics people could talk about to each other in their everyday lives?but don't." In addition, many researchers who have used focus groups due to "their perceived convenience, allowing for a large amount of data to be collected in a relatively short space of time from multiple informants" (Barbour 1995). For these reasons we decided to incorporate focus groups as the qualitative element in our 
6.2 Research has demonstrated that mixed sex groups are "far less willing to discuss issues freely" (Halstead and Waite 2002: 17), therefore it is common in sexual health research or interventions to separate groups by gender (e.g. Halstead and Waite 2002; Low et al. 2003; Roberts et al. 2005; Stewart and Shamdasani 1990). In our evaluation all focus groups were separated by gender because of both the potential sensitivity of the discussion topic, and the age of our study population, which ranged from 12-13 years old (S1 groups) or 16-17 years for S5 pupils. A male researcher facilitated all focus groups with young men and a female researcher facilitated the groups with young women. All groups were held on the premises of the participating secondary schools. Focus group discussions lasted between 35 to 50 minutes. For a few S.1 (Secondary 1) groups, teachers stayed in the room, usually doing marking or work preparation in a corner of the classroom, but none of them participated in the group discussions. In the groups with older pupils (S.5) teachers always left the room.

\section{Data collection}

7.1 Trained group facilitators used a topic guide with a number of starter questions and vignettes to ensure key sexual health education concerns were raised in each focus group. The issues were very similar for young men and women in each age group, for example for the S.5 group one question to both genders was: 'If you are having relationship problems with your girlfriend or boyfriend, who can you talk to about this?' This question also highlights the fact that focus group facilitators tried to avoid the idea that the focus group addressed only heterosexual relationships. The questions designed for S.1 focused more on knowledge and attitude, whilst those for S.5 also included some behavioural questions. All focus groups were audiorecorded with permission from the young people and the school authorities. Facilitators used a small taperecorder with a separate table microphone. The tapes were transcribed verbatim.

\section{Sample}

8.1 We aimed to recruit one school within an urban catchment in an area of social disadvantage, one in a more 'advantaged' urban area and one rural school. This allowed the study to encompass a range of the different types of school environment in the region. Although recruiting schools participating in Healthy Respect within these categories was not difficult (Table 1), recruiting similar comparison schools proved more challenging. Similar difficulties were experienced recruiting schools to the quantitative questionnaire survey (Tucker et al. 2005). Only one comparison school agreed to co-operate for this qualitative part of the study (see Table 1).

\section{Table 1 Characteristics of focus groups}

\begin{tabular}{|l|c|c|c|c|}
\hline & \multicolumn{2}{|c|}{ Females } & \multicolumn{2}{c|}{ Males } \\
\hline School catchment area & S.1 & S.5 & S.1 & S.5 \\
\hline Rural \& mixed socio-economic catchment & 2 & 2 & 2 & 2 \\
Urban \& higher socio-economic catchment & 2 & 2 & 2 & 2 \\
Urban \& lower socio-economic catchment & 4 & 4 & $4^{*}$ & $4^{*}$ \\
Total focus groups & 8 & 8 & 8 & 8 \\
\hline
\end{tabular}

* = School had organised focus groups with S.6 rather than S. 5 as requested.

\section{Analysis}

9.1 The qualitative data analysis took place through reading and re-reading the transcripts. A thematic approach was used to code transcripts for recurrent themes (Forrest Keenan et al. 2005). Illustrative quotes from these transcripts have been used to illustrate the key themes and sub-themes and these are identified in the text below by school year (e.g. S.1) and gender (e.g. female). For instance, we use 'Males S.1' for: focus groups with young men in school year Secondary 1. Context specific information regarding the school or the school's surrounding areas is provided as and when required, but only where anonymity can be maintained. We report the S.1 and S.5 pupils separately as sexual health knowledge and experience is age-related and hence often quite different. This was to be expected, as S.1 pupils were about 12 years old and those in S.5 about 15 and 16 years old, hence there was a substantial difference in knowledge and experience between these age groups. Similarly quotations from the boys and girls are presented separately. In the quotes below the words of focus group participants are represented in standard text, 
whilst the words of the focus group facilitator are written in bold.

\section{Results}

10.1 The findings are listed under a number of sub-themes, including gender, parents, sex education at school, sexual health services and advice.

\section{Gender differences}

10.2 Terms such as 'embarrassed' or 'embarrassment' were less often used in the boys' focus groups than in the girls' focus groups. The boys only made an occasional use of the term 'embarrassment', for example when discussing a sex-education video:

- You were meant to put your hand up, you were made to put your hand up.

- Oh yes, that was (interrupted) ...

- You have to put your hands up or you would get asked and yet if you did put your hand up you got asked anyway ... (inaudible)

- You had to say like, the vagina has hairs on it.

- Aye, you had to say embarrassing stuff and that. Everybody was laughing at me. And I went shut up or I will punch your ... (inaudible).

Males S.1

10.3 One girls' group mentioned the perception of gender differences in terms of embarrassment. The girls perceived that the boys would be less embarrassed about them seeing pictures of naked men than they were about the thought of boys seeing images of naked women. In one female focus group girls mentioned being embarrassed about the boys in their school year seeing such images:

- It wasn't embarrassing when you saw the boys', .. the men's stuff and all that.

- It was more embarrassing because the laddies (=boys) were seeing pictures of naked women. Females S.1

10.4 At the same time this group of girls did not think that the boys would be embarrassed about girls seeing naked male bodies:

- Do you think they were embarrassed when you were seeing the pictures of the naked men?

- No.

Females S.1

10.5 One of the girls' groups perceived a contradiction in the embarrassment of the boys, when highlighting the lack of discussion around the use of contraceptives:

- Aa, but maybe they are too embarrassed and they want the girl to say: 'Oh you've got that (=contraceptive pill)

- But they are not embarrassed to ask you in the first place to get into bed with you. Females S.5

10.6 Some of the boys suggested they would speak to their (male) friends about sexual health issues, because:

- 'You don't feel so embarrassed in front of your mates. Males S.5

\section{Being able to speak to parents}

10.7 There were generally mixed feelings about speaking to parents about sexual health issues, for example:

- I can't tell my mum anything like that.. (Inaudible)

- If she goes: "Oh how is everything?", It's like: "Fine".

- I can't tell my dad. He'll tell everyone.

- My dad's embarrassing.

- .......

- I just tell my mum.

Female S.1 
10.8 And in another focus groups with girls:

- How easy is it to go to your parents?

- Not very

- Not at all.

Female S.1

10.9 Following the introduction of the vignette about whom the young people would speak to about relationship problems, one female focus group participant replied

- Why wouldn't you speak to your parents?

- I'd be too embarrassed.

Females S.1

10.10 Similarly, girls in another group commented about approaching their parents:

- How easy is it? How approachable are they? How easy is it for you to (interrupted) ...

- It's embarrassing. You don't know what they are going to say.

- It's a bit embarrassing cos (=because) they're so open.

- I've heard my granny talking (inaudible) before and it's embarrassing, because then they remember that and they embarrass you when you're older.

- You tell your mum that when you're young and then when you're all grown up and you've got boyfriends she tells them all the embarrassing stories.

- Females S.1

10.11 The focus groups with older pupils spoke less often about embarrassment, and when they did it was about other people being embarrassed (i.e. not the individual focus group participant) or having overcome it, for example, in one of the young men's group, one participant spoke about a testicular lump:

- If I had something wrong with myself like cause like I had a lump a wee while ago and I was like well crapping my pants and I spoke to my mum about it first and it went away, but I was going to go with my mum though, but it's still embarrassing for me, cos (=because) I've had like mine checked like twice and it was quite embarrassing for the guy.

Males S.5

This quote also suggests that the participant felt that the doctor who had to check his testicles was embarrassed.

10.12 In one focus group with older boys it was suggested that some people could talk to their parents if they were close to them, or to other relatives who were slightly more removed, such as cousins and uncles.

- If you are close to your parents then you can talk to them.

- Your cousins, uncles, people like that who are not family in general, you wouldn't feel so embarrassed speaking about it to.

Males S.5

10.13 The suggestion was that it was less embarrassing to speak to these relatives, probably because you don't see them everyday at home, as the same group explained why they would not speak to a guidance teacher about relationships:

- You could speak to your uncle maybe once every few weeks or once in a week, if you speak to the guidance you have to see them everyday.

Males S.5

\section{Embarrassing sex education at school}

10.14 In reply to the question whether sex education in primary school could be improved, the immediate answer in some groups was:

- Yes (several pupils agreeing).

- Okay, give me some examples. What was wrong with it?

- It was dead embarrassing.

- It was disgusting.

- Disgusting.

- Cos (=because) all the boys were going: "Oooh, look at that" and all the girls, well half the girls in our class, well we were all sitting laughing, and we were all like that, you know like that, and like, all 
the girls went: "Oooh, look at that", and then the boys started going like and getting embarrassed and that as well ...

Females S.1

10.15 Some groups distinguished between more or less embarrassing situations in their primary school sex education, for example when the facilitator seemed to have picked up that there was an element of embarrassment and asked:

- It was embarrassing was it?

- No, it was just fun

- It was more embarrassing in primary 7 when we started talking about ejaculation and all that stuff. Females S.5

10.16 In the same group a few minutes later the girls made some negative comments about a particular teaching device used in primary school:

- And then we had a wee question box as well.

- And nobody used it at all.

- Oh, yeh.

- It was so embarrassing it was.

- It was ridiculous.

Females S.5

10.17 In other groups suggestions were also put forward as to how to improve the primary school sex education, but sex education was not seen as embarrassing, for example:

- And thinking back, was that a huge embarrassment what you got at the time?

- No, no, no (several replying at the same time). Females S.5

10.18 When asked if pupils could speak to their teachers about relationships, several groups were adamant that they would not discuss such issues with their teachers. For example:

- Someone also mentioned guidance teachers, could you speak to your guidance teachers?

- No way.

- I could but I wouldn't.

- No because it's too embarrassing.

- You wouldn't want to speak to them like stuff like that, you want to stay as far away from them as possible.

Males S.5

10.19 Some pupils feared that teachers might not treat you like an adolescent, but as a child, for example:

- Sometimes if you speak to a teacher they might treat you like a kid and you get embarrassed. Males S.5

\section{Sexual health services and advice}

10.20 Pupils mentioned being embarrassed about approaching sexual health services and getting condoms in particular:

- Do you know why people don't buy condoms? Cos (=because) they're too embarrassed to get them. Females S.1

10.21 Barriers to condom use included embarrassment and price.

- If you're embarrassed and don't want to buy them. Females S.5

10.22 And later on in the same focus group one of girls stated:

- And I don't think people would be as embarrassed as some people would think, because people can go to their guidance teacher and nobody knows or people who are embarrassed can go to their friends and stuff, you know, like it would be easier.

Females S.5 
10.23 Going for sexual health advice was equally embarrassing for young people, even for those who had stated that they would go and see a doctor for sexual health issues. For example:

- I would rather read a book and find out for myself than see anybody. I would rather, I would be too embarrassed to say I didnae ken (=didn't know) what it was.

- But you said that you would go to the doctor, would you go there for advice?

- I could go there for advice, for help if I was needing.

- I wouldnae dae (=wouldn't do) anything unless it was serious, I wouldn't just go "what's this mean?" Males S.5

10.24 One of the girls' and one of the boys' groups expressed reservations about having to see a male GP with a sexual health problem. The girls hinted at both confidentiality and gender / embarrassment issues:

\section{Would you go to your family doctor?}

- Nuh. (=no)

- Nuh, I wouldn't go to him, he'd tell my mum.

- It's a guy.

Females S.1

10.25 Whilst boys in one of the younger focus group, showing both bravado and a dose of homophobia, suggested that a doctor from the opposite sex was 'highly' desirable,

- I've got a female GP.

- Would you go to a female GP?

- Damn straight, yes.

- Anyone who would not go to a GP? Is everybody comfortable with going to a GP?

- I'm not. It has to be female work. It has to be somebody... It wouldn't me like, but if the guy came over to me and started touching me like

Males S.1

10.26 Although embarrassment was not explicitly mentioned there were also gender issues. When asked to whom they could speak about sexual health problems, some participants said they would see their doctor, but others raised the issue of the gender of their GP, for example:

- Speak about a problem with my doctor.

- My doctor's a man, I am not telling him that.

Females S.5

10.27 For some the anonymity of a specialist agency such as health promotion was an advantage. When the facilitator asked whether or not the young people would approach specialist agencies for advice, the positive reply was phrased in terms of a one-off encounter, i.e. there was no 'need' for embarrassment as the agency staff did not know them and the young people saw themselves as unlikely ever having to return:

- What about specialist agencies like, Health Promotions (=the local health promotion agency) and Family Planning?

- I think that would be pretty easy, because you can basically say that you are never going to see them. And you could be more open with them than you could be with people that you see on average, two or three times a week.

Males S.5

10.28 There was a mixed reaction in some of the groups about whether going to a family planning clinic was embarrassing. For example, when the facilitator asked in one group of girls whether or not they could just walk into the local family planning clinic, the reply was:

(Laughter)

- Yeah, but it is pretty embarrassing as well.

- No it's not.

- Aye, it is.

Females S.5

10.29 However, in one of the young men's groups embarrassment was mentioned in relation to using sexual health services. The facilitators asked:

- Okay, if considering the family planning clinic, what might stop young men from using it? 
- Get embarrassed

- (Agreement)

- Yeah that would be about it.

Males S.5

10.30 The young men in the same group did link this embarrassment to the Scottish psyche, mentioning the mass media:

- Was there not something on the news about that saying just in general about men's health that they feel more embarrassed to go to the doctors and stuff like that sort of in general not just sexual health, but like over Scotland men are embarrassed if there is something wrong with them and that would stop them going.

Males S.5

Phone line and Internet services were regarded by some as more anonymous and hence less embarrassing to use, for example:

- You don't feel so embarrassed on the phone. Males S.5

\section{Embarrassment of others}

10.31 It was not only the pupils in the focus groups who experienced embarrassment; they also suggested that some parents and some teachers showed signs of being too embarrassed to talk about the topic. For example, some times pupils said they could speak to one parent, but not the other. One or two boys could not speak to their mother:

- So we'll start with parents. Can you speak to your parents?

- Only my dad. My mum would get all funny. Males S.1

10.32 Some teachers were also regarded as being embarrassed about having to teach sex education and speak about sex, for example:

- I think that most of the teachers are too embarrassed to teach it and that sort of thing (interrupted)

- Totally

- ...especially in primary 7 and stuff like that when you've got kiddies giggling and you know pointing bits out to each other

- It's like when they're speaking, they'll be talking to you in a completely normal tone and then it will be like (whispers) 'penis'!

- (Laughter)

Males S.5

10.33 Similarly, in a girls group when the facilitator asked whether teachers were keen to teach more sex education than the school prescribed, the reply focused on embarrassment:

- ..., do you think they (=teachers) would like to tell you more but they are limited by the syllabus?

- I think they are just embarrassed.

- I think they are embarrassed as well, we are but, but I mean we are in school we need to learn more instead of like the things that we already know, you know like our Mum's have told us, so we need to learn more about it.

Females S.5

10.34 There was much less mention of embarrassment in the older age group, and if it was mentioned at all it was in reference to other people, for example, when a young women's group in S.5 were talking about condoms:

- If you're embarrassed and don't want to buy them. Females S.5

10.35 One group suggested that it might be useful to get someone with a STI to come and talk to them as part of school-based sex education. However, one group member immediately suggested that this might be embarrassing for that person:

- Maybe you could get someone in who has one of these diseases, and ask them how it has changed 
their life.

- Yeah, but that might be too embarrassing for the person.

Males S.5

10.36 It was common for pupils in S.5 to talk relatively freely about their own sex life. In reply to the question about who is on the pill, for instance, one of the group members replied:

- I am, but that's cos (=because) I'm in a long-term relationship. I've been going with my boyfriend for two years. We were using condoms and that and we both went and got tested and we were fine so I just went on the pill.

- Did you?

- Oh, that's really sensible. Females S.5

\section{Discussion}

11.1 Embarrassment played a greater role in the way young people discussed issues around sexual health and sex education than expected. Focus group participants referred not only to their own embarrassment, but also to that of significant others, including their parents, friends, teachers and health care providers. For example, young people reported to be too embarrassed to speak to their parents, or they perceived their parents themselves to be embarrassed or they thought that their parents might embarrass them when it came to issues around sexual health and sex education. Similar findings were reported in a recent study of sexual relationships among teenagers in a multicultural area of London. There, with some exceptions, the participants across ethnic groups shared "a reluctance to talk to parents and expressed feelings of embarrassment, discomfort and scepticism that parents might be able to understand them and their relationships" (Sinha et al. 2006: 4.1). Despite such reservations many young people claimed that parents should be a key source of information about sex (Office for Standards in Education 2002). Whilst Buckingham and Bragg (2004) reported that, in interviews with 120 young people aged 9 to 17 in England, some expressed a preference for finding out about sex from their parents. After providing a quote illustrative of a parent-child relationship, i.e. 'I can talk freely with my mum about sex...' they commented that such a "matter-of-fact approach appeared to be rare" (Buckingham and Bragg, 2004: 57). Adolescents are also likely to be concerned over confidentiality or embarrassment when obtaining condoms from shops, pharmacists of family planning clinics (Klein et al. 2001; Sixsmith et al. 2006).

11.2 Embarrassment is probably also age related as Low and colleagues (2003: 832) found in their study of adolescents: "only $7 \%$ of those tested felt embarrassed" about providing a urine sample for testing for Chlamydia trachomatis and Neisseria gonorrhoeae. However, physically giving a urine sample is not the same as the more personal act of talking about sexual health. Equally it is recognised that adults in the UK may also be embarrassed about approaching sexual health services, such a genito-urinary clinics (MacDonald 1998: 73), a point also picked up by Free and colleagues (2002) in their qualitative study of (non-)use of emergency contraception. Free et al. (2002: 1395) quoted a 21-year-old woman recalling her experience of using sexual health services: "And then when I went there I was still nervous but when they actually spoke to me they made me feel relaxed so I was OK ... and as I've got older there is nothing to be embarrassed about."

11.3 In this study one could ask to what extent school norms in Aberdeen and Edinburgh or the wider Scottish or British culture shaped pupils emotions in relation to sexual health issues. On the latter, Buckingham and Bragg (2004: 12) reminded us about the British reputation for being 'uptight' about sexual matters, whilst Weyman (2003: 6) argued, "great British reserve and embarrassment frequently prevents open discussion" between young people and their parents. Although embarrassment about sex is not restricted to British culture, for example, Roberts and colleagues (2005: 1491) noted that Mongolian youths "talked about the embarrassment that they felt when talking about sexual matters, whether it was with sexual partners, friends, parents or teachers." Indeed the very reason Goffman (1956) focused on embarrassment is its universal nature. "Face-to-face interaction in any culture seems to require just those capacities that flustering seems to destroy. Therefore, events which lead to embarrassment and the methods for avoiding and dispelling it may provide a cross-cultural framework of sociological analysis" (Goffman 1956, 266). Displaying embarrassment serves as an apology for that (imagined) mistake, and "simultaneously demonstrates one's awareness of social mores and thus one's commitment to membership of society" (Buckingham and Bragg 2004: 187).

11.4 Emotion is also relational and contextual (Lyon and Barbalet 1995) and in our study we can see how the embarrassment factor is related to, for instance, a shared experience of sexual health education with both genders present. The shared discourse around 'embarrassment' and sexual health issues is also rendered visible because of the relational nature of emotion. 'Feeling' embarrassed is not necessarily something that one does alone, but rather is experienced through interaction with others. The relational 
aspect of emotion then raises the interesting possibility that sexual health education might benefit from targeting individual rather than group-learning experiences.

\section{Embarrassment and sex education}

12.1 Wellings and colleagues (2001) reported that young men who talked to their parents about sex tended to use contraception more often when compared to those who did not do so. This is all the more reason for health educators to address issues around embarrassment. The social context in which young people have sexual relationships combined with their stage of emotional development has an impact on how they view and address (or not) issues around sexual health. Of course, sexuality and its expressions do not occur outside of culture (Keys et al. 2006: 65). As young people and adults are part of a British (Scottish) culture, which is not known to be at ease with discussing such issues openly, one can see embarrassment creeping in. This, as MacDonald (1998: 76) reminded us, also means that promoting sexual health "is a complex dialogue between health promoter and the client and the ability of both to put those health education messages into practice." At the same time one can identify some of Hochschild's 'feeling rules', for example in the quote used above: " ... I don't think people would be as embarrassed as some people would think ...". The UK reader will recognize the feeling rule that 'adolescents are embarrassed about sex'. The expectation is that young people will be embarrassed about it.

12.2 Buckingham and Bragg (2004: 58) suggested that frequently parents and children appeared to agree that children 'knew it all ready', on the grounds that this would make it unnecessary to raise the matter, and hence spare the embarrassment. At the same time many parents in their study "were keen to insist that they were more open with their children than their own parents had been with them" (Buckingham and Bragg 2004: 187). Our findings suggest that some of the assumptions of school-based sex education, for example, that sex is not embarrassing and that everything can be discussed, might be insensitive to young people's emotions. Embarrassment among young people about certain issues might well be age-related, or more precisely related to the different rates of emotional development in young people. Embarrassment may also take different forms for young men and young women as research by Holland et al (1990) suggested. In addition Frosh et al. (2002: 12) in discussing masculine identity formation, suggest, in relation to dealing with their social worlds, that 'While boys asserted themselves as tough and active, several of them described girls as more mature evidenced in their attitudes to school work, friendships and their ability to be serious and to give emotional confidences."

12.3 How can we reduce the 'embarrassment' factor related to sex education, sexual health in general and sexual health services in particular? Sex education interventions have focused successfully on reducing embarrassment, for example in buying condoms using behavioural training (Weisse et al. 1995). Perhaps sexual health education interventions need to address young people's feelings of embarrassment and make them explicit, along the lines of the information campaigns to reduce embarrassment around coming forward for cervical screening (Sutton and Rutherford 2005).

12.4 Buckingham and Bragg (2004: 59) reported that children with older siblings (particularly same sex ones) frequently claimed that they were better off in terms of learning about sex and relationships. These young people also often could use age-appropriate slang words with siblings, which they could not use with parents. Marrying these findings with our own suggests that there is a strong case for same sex peer group education, using self-help materials. This could be done within a classroom setting, with a teacher supervising the handing out of self-help materials.

12.5 Teachers rarely feel well prepared or supported as their initial teacher training does not always include work on sexual health and relationships and continuing professional development opportunities vary widely across the country (Warwick et al. 2005).

12.6 Nevertheless, some evidence suggests that young people see schools as legitimate settings in which they should be able to learn about sexual health and sexuality (Rolston et al. 2005), which is also supported by our findings. However, some of the focus group discussions highlighted the desire for anonymity and how this lessened feelings of embarrassment around sexual health matters. Clearly there is a role for trained outside specialist teachers or health promotion workers to take on this role as peripatetic workers within school settings.

\section{Strengths and weaknesses of focus-group method in this study}

13.1 The key strength of this study is that in common with much of qualitative research, namely the explorative approach. In our case, the focus group analysis highlighted embarrassment as a key issue, something we had not specifically included in our focus group schedule. Finlay (1996: 92) reminded us that in "the mainstream research-methods literature, there would appear to be a complacent assumption that qualitative methods are appropriate to the study of emotions." The school-based focus groups were largely 
drawn from pre-existing groups of school classes. The advantage of using a pre-existing group is that if participants already know each other they may feel more at ease to take an active part in the discussion and/or to contradict each other. However, this is tempered by the possibility that people who know each other and work with each other on a day-to-day basis might not speak openly about embarrassing issues. Our focus group facilitators encouraged the young people not to give personal accounts, but to discuss the kind of sexual health issues that were relevant for people of their age. However, the younger participants and the more confident older participants regularly spoke in the first person singular. Generally, the younger groups took less than the full teaching slot to address the issues on our topic guide, whilst older pupils had usually more to say on the matter and filled the whole allocated slot.

13.2 Occasionally there were embarrassing moments during the focus groups, particularly where these involved younger boys some of whose comments were clearly designed to embarrass fellow pupils in the focus group. On such occasions the facilitators stressed that they were not interested in the behaviour or experience of individuals in the group, they also tried not to laugh at the expense of the group members despite some very funny comments by young people.

13.3 There was also a fair amount of laughter as highlighted in some of the quotes used as illustration above. Some laughter was undoubtedly due to embarrassment and some simply to relieve tension. Some of these could be seen in the light of Hochschild's (1983) work on emotion management. However, not all laughter relates to embarrassment as Macnaghten and Myers (2004: 70) noted in their focus groups: "... laughter suggests a shared sense of what is appropriate for this group." Returning to Billig's notion mentioned above that humour aids the creation of the social reality of embarrassment, we would offer a word of warning to those trying to address embarrassment in sexual health matters using (a lot of humour, as they may find that this approach actually strengthens the embarrassment by reproducing and reinforcing it.

\section{Conclusion}

14.1 Embarrassment exists among young people around issues related to sex education and sexual health services, but it seems to decline when young teenagers grow older. Not only are there elements of sexuality, sexual health and sex education that (some) young people themselves perceive to be embarrassing, they also sense embarrassment in adults providing them with sexual advice/education, including teachers, parents and health professionals.

14.2 It is important for policy makers, teachers and sexual health promoters to acknowledge and understand young people's emotions, especially feelings of embarrassment, in order to be able to improve future sex education and advice as well as being able to anticipate potential barriers among young people. If humour reinforces the notion that something is embarrassing, as the literature suggests, sex educators need to be careful not to introduce too much humour in school-based sex education programmes. Furthermore, if for young people, as for many of us, avoiding embarrassment is a compelling drive (Miller 1996: 164); this is bound to act as a barrier in the teaching and learning of sex education and the uptake of sexual health services among young people.

14.3 For sociologists, sexual behaviour is part of social action, because "it not only influences, and in turn is influenced by, other factors but it also supplies a motive for action" (Jones and Jones, 1975: 88). The sociological question is perhaps: 'Why and how does such embarrassment continue to exist?' Is it related to social control or maintaining social order, as Goffman (1967) suggested, especially internalized selfcontrol? Perhaps the key challenge for those developing sexual health education interventions for young people is to deliver the curriculum in a format that might minimise one of the main barriers to the take-up of sexual health messages, namely, embarrassment. Further sociological research would enable us to better understand the nature of and the reasons for embarrassment around sexual health and sex education among young people, and ultimately help to design strategies to reduce such embarrassment.

\section{Acknowledgements}

We would like to thank the participating pupils, the schools and teachers who facilitated the research, and Diarmid Harris and Jilly Ireland for advice on an earlier version of the focus group topic guide. The evaluation was supported by a grant from the Chief Scientist Office of the Scottish Executive Health Department (Edinburgh). Finally, we also like to thank the anonymous reviewers for Sociological Research Online for their helpful comments. 
BARBALET, J. (ed.) (2002) 'Introduction: why emotions are crucial', Emotions and Sociology. Oxford, Blackwell Publishing.

BARBOUR, R.S. (1995) Using focus groups in general practice research, Family Practice, 12: pp 328-234.

BILLIG, M. (2001) Humour and Embarrassment: Limits of 'Nice-Guy' theories of social life, Theory, Culture \& Society, 18: pp.23-43.

BOWLING, A. (2002) Research Methods in Health: investigating health and health services $\left(2^{\text {nd }}\right.$ edn), Maidenhead: Open University Press

BUCKINGHAM, D. and BRAGG, S. (2004) Young People, Sex and the Media. The Facts of Life, Houndsmills, Basingstoke: Palgrave Macmillan

BULLOCK, S. and ROOM, R. (2006) Drinking behaviour, coming of age and risk. In: AGGLETON, P., BALL, A. and MANE, P. (eds.) Sex, Drugs and Young People: International Perspectives, London: Routledge, pp.120-137.

CHAPPLE, A. and ZIEBLAND, S. (2004) The role of humour for men with testicular cancer, Qualitative Health Research, 14: 1123-1139.

COLES, B. (1995) Youth and Social Policy: youth citizenship and young careers. London: University College of London Press

CORBETTA, P. (2003) Social Research: Theory, Methods and Techniques, London: Sage.

DICENSO, A., BORTHWICK, V.W., BUSCA, C.A., CREATURA, C., HOLMES, J.A., KALAGIAN, W.F. and PARTINGTON, B.M. (2001) Completing the picture: adolescents talk about what's missing in sexual health services. Canadian Journal of Public Health, 92: 35-38

FINLAY, A. (1996) Teenage pregnancy, romantic love and social science: an uneasy relationship. In: JAMES, V. and GABE, J. (eds.) Health and the Sociology of Emotions , Oxford: Blackwell, pp. 79-96.

FREE, C., LEE, R.M. and OGDEN, J. (2002) Young women's accounts of factors influencing their use and non-use of emergency contraception: in-depth interview study. British Medical Journal 325: 1393-1396.

FORREST KEENAN, K., TEIJLINGEN VAN, E.R. and PITCHFORTH, E. (2005) The analysis of qualitative research data in family planning and reproductive health care, Journal of Family Planning \& Reproductive Health Care 31: 40-43.

FROSH, S., PHOENIX, A. and PATTMAN, R. (2002) Young masculinities, London: Palgrave.

GIBBS, A. (1997) Focus Groups, Social Research Update Issue 19, (Edited by N. GILBERT), Guildford: University of Surrey. Web address: http://www.soc.surrey.ac.uk/sru/SRU19.html

GOFFMAN, E. (1956) Embarrassment and social organization. American Journal of Sociology 62, 264-271 GOFFMAN, E. (1967) Interaction Ritual. New York: Pantheon Books.

HALSTEAD, M. and WAITE, S. (2002) 'Worlds Apart': The sexual values of boys and girls. Education and Health 20: 17-23

HAY, J. (2000) Functions of humor in the conversations of men and women. Journal of Pragmatics, 32: 709-742.

HOCHSCHILD, A.R. (1979).'Emotion work, feeling rules, and social structure', American Journal of Sociology 85: 551-575.

HOCHSCHILD, A.R. (1983) The Managed Heart Commercialization of Human Feeling. Berkeley: University of California Press.

HOLDSWORTH, C. and MORGAN D. (2005) Transitions in Context: Leaving home, Independence and Adulthood, Maidenhead, Berkshire: Open University Press

HOLLAND, J., RAMAZANOGLU, C., SCOTT, S., SHARPE, S. and THOMSON, R. (1990) 'Don't die of ignorance, I nearly died of embarrassment. Condoms in context. WRAP Paper 2, London: Tufnell Press.

HOLLAND, J., RAMAZANOGLU, C., SHARPE, S. and THOMSON, R. (1992) 'Pressure, resistance, 
empowerment: Young women and the negotiation of safer sex' In AGGLETON, P, DAVIES, P. and HART, G. (eds.). AIDS: Rights, Risk and Reason, London: Falmer Press, pp. 142-162

HYDE, A., HOWLETT, E., BRADY, D. and DRENMAN, J. (2005) The focus group method: Insight from focus group interviews on sexual health with adolescents, Social Science \& Medicine 61: 2588-2599.

JONES, R.K. and JONES P.A. (1975) Sociology in Medicine, London: The English Universities Press Ltd.

JONES, G. and WALLACE, C. (1992) Youth, Family and Citizenship. Milton Keynes: Open University Press.

KEGAN, R. (1996) Neither 'safe sex' nor 'abstinence' may work-Now what? Toward a third norm of youth sexuality. In D. CICCHETTI and S.C. TOTH (eds.) Adolescence: Opportunities and challenges, Rochester, NY: University of Rochester Press: 125-147.

KEYS, D., ROSENTHAL, D. and PITTS, M. (2006) 'Young people, sexual practice and meanings'. In: Aggleton, P., Ball, A. and Mane, P. (eds.) Sex, Drugs and Young People: International Perspectives , London: Routledge, pp.120-137.

KITZINGER, J. (1995) Qualitative research: introducing focus groups, British Medical Journal 311: 299-302.

KLEIN, J., ROSSBACH, C., NIJHER, H., GEIST, M., WILSON, K., COHN, S., SIEGEL, D. and WEITZMAN, M. (2001) Where do adolescents get their condoms?, Journal of Adolescent Health 29: 186193.

KREUGER, R.A. and CASEY, M.A. (2000) Focus Groups (3 ${ }^{\text {rd }}$ edn), London: Sage.

LOW, N., CONNELL, P., MCKEVITT, C., BAGGILI, T., TENANT-FLOWERS M., MORE, C., ZUCKERMAN, M., HAMILTON, M., JONES, J., BLAKE, M. and STERNE, J.A.C. (2003) 'You can't tell by looking': pilot study of a community-based intervention to detect asymptomatic sexually transmitted infections, International Journal of STD \& AIDS : 14: 830-834.

LYON, M. and BARBALET, J. (1995) Society's body: emotion and the "somatization" of social theory. In: CSORDAS T.J. (ed.) Embodiment and Experience: The existential ground of culture and self, Cambridge: Cambridge University Press, pp. 48-67.

MACDONALD, T.H. (1998) Rethinking Health Promotion: A global approach. London: Routledge.

MACNAGHTEN, P. and MYERS, G. (2004) Focus groups. In: SEALE, C, GIAMPIETRI, G, JABER, F, SILVERMAN, D. (eds.) Qualitative Research Practice, London: Sage.

MCVEA, J., ROSS, M., DE CAESTECKER, L., MILNE, D., MCEWEN, A., REES, N., WILKIE, L. and MORTON, C. (2001) The national health demonstration projects. Health Bulletin (Edinburgh), 59: 268-275.

MILLER, R.S. (1996) Embarrassment. New York: Guilford Press.

OFFICE FOR STANDARDS IN EDUCATION (2002) Sex and Relationships Education in Schools, London: OFSTED.

PARRATT, J. and HAY, D. (2003). Sexually transmitted infections. Current Obstetrics and Gynaecology, 13: 224-231.

PARROTT, W.G. and HARRÉ, R. (eds.) (1996) Embarrassment and the threat to character. The emotions: social, cultural and biological dimensions. London: Sage, pp.39-56.

ROBERTS, A.B., OYUN, C., BARNASAN, E. and LAING, L. (2005) Exploring the social and cultural context of sexual health for young people in Mongolia: implications for health promotion, Social Science \& Medicine, 60: 1487-1498.

ROLSTON, B., SHUBOTZ, D. and SIMPSON, A. (2005) Sex education in Northern Ireland schools: a critical evaluation. Sex Education, 5: 217-235.

ROSENTHAL, D.A. and SMITH, A.M.A. (1997) Adolescent sexual timetables. Journal of Youth and Adolescence, 26: 619-636.

SCHAIE, K.W. and WILLIS, S.L. (1991) Adult Development and Ageing (3 $3^{\text {rd }}$ edn.), New York: HarperCollins Publishers. 
SCOTTISH OFFICE DEPARTMENT OF HEALTH. (1999) Towards a Healthier Scotland. A White Paper on Health. Edinburgh, The Stationery Office: 28-9.

SIXSMITH, J., GRIFFITHS, J., HUGHES, J., WREN, J., PEMFOLD, S., NATUSCH, H. (2006) Accessiblity of condoms to young people in Manchester, UK. Journal of Family Planning \& Reproductive Health Care, 32: 219-225.

SHILLING, C. (2002) The two traditions in the sociology of emotions. In. J. BARBALET (ed.) Emotions and Sociology. Blackwell Publishing, Oxford: 10-32.

SHOVELLER, J.A. and JOHNSON, J.L. (2006) Risky groups, risky behaviour, and risky persons: Dominating discourses on youth sexual health. Critical Public Health, 26: 47-60.

SINHA, S., CURTIS, K., JAYAKOBY, A., VINER, R. and ROBERTS, H. (2006) Family and Peer Networks in Intimate and Sexual Relationships Amongst Teenagers in a Multicultural Area of East London, Sociological Research Online 11(1), web address: http://www.socresonline.org.uk/11/1/sinha.html (accessed Sept. 2006).

STEWART, D.W. and SHAMDASANI, P.N. (1990) Focus groups: Theory and Practice. Sage, Newbury Park, CA.

SUTTON, S. and RUTHERFORD, C. (2005) Sociodemographic and attitudinal correlates of cervical screening uptake in a national sample of women in Britain, Social Science \& Medicine, 6: 2460-2465.

TENHOUTEN, W.D. (2007) A General Theory of Emotions and Social Life . Routledge, London

TUCKER, J. PENNEY G., SHUCKSMITH, J., VAN TEIJLINGEN E., PHILIP, K., FITZMAURICE A., IMAMURA, M., GUTHRIE, L., REID. J., PENFOLD, S. and OLIPHANT, R. (2005) External Evaluation of Healthy Respect, a national health demonstration project: Summary Final Report, Edinburgh: Scottish Executive Health Department.

TUCKER, J., VAN TEIJLINGEN, E., PHILIP, K., SHUCKSMITH, J. and PENNEY, G. (2006) Health Demonstration Projects: Issues in evaluating a community-based health intervention programme to improve young people's sexual health, Critical Public Health, 16: 175-189.

TEIJLINGEN VAN, E.R. and PITCHFORTH, E. (2006) Focus Group Research in Family Planning and Reproductive Health Care, Journal of Family Planning \& Reproductive Health Care , 32: 30-32

WARWICK, I., AGGLETON, P. and RIVERS, K. (2005) Accrediting success: evaluation of a pilot professional development scheme for teachers of sex and relationship education. Sex Education, 5: 235253.

WEISSE, C., TURBIASZ, A. and WHITNEY, D. (1995) Behavioural training and AIDS reduction: overcoming barriers to condom use. AIDS Education \&Prevention, 7: 50-59.

WELLINGS, K., NANCHAHAL, K., MACDOWALL, W., MCMANUS, S., ERENS, B., MERCER, C.H., JOHNSON, A.M., COPAS, A.J., KOROVESSIS, C., FENTON, K.A., and FIELD, J. (2001). Sexual behaviour in Britain: early heterosexual experience. The Lancet 358: 1843-1850.

WENTWORTH, W.M. and YARDLEY, D. (1994) Deep sociality: A bioevolutionary perspective on emotions. In: WENTWORTH, W.M. and RYAN, J. (eds.) Emotions in Social Life: Critical Themes and Contemporary Issues. London: Routledge, pp. 21-55.

WEYMAN A. (2003) Promoting sexual health to younger people: Preventing teenage pregnancy and sexually transmitted infections. The Journal of the Royal Society for the Promotion of Health 123: 6-7.

WIGHT, D. (1994) Boys' thoughts and talks about sex in a working class locality of Glasgow. The Sociological Review 42: 703-737.

WIGHT, D., HENDERSON, M., RAAB, G., ABRAHAM, C., BUSTON, K., SCOTT, S. and HART, G. (2000) Extent of regretted sexual intercourse among young teenagers in Scotland: A cross sectional survey. British Medical Journal, 320: 1243-1244.

WIGHT, D., RAAB, G. M., HENDERSON, M., ABRAHAM, C., BUSTON, K., HART, G. and SCOTT, S (2002) Limits of teacher-delivered sex education: interim behavioural outcomes from randomised trial. British Medical Journal, 324: 1430-1434. 
WILLIAMS, S. (1998) Modernity and the Emotions: Corporeal Reflections on the (Ir)rational. Sociology, 32: 747-769. 